\title{
Further Observations on the Differential Inhibition of Coliform Bacilli and Rough Variants of Intestinal Pathogens
}

\author{
BY J. BRODIE AND W. SHEPHERD \\ Department of Bacteriology, University of St Andrews Medical School, Dundee
}

\begin{abstract}
SUMMARY: The pattern of differential inhibition of Gram-negative bacilli of intestinal origin depends not only upon a synergy of bile salts and electrolytes of the Hofmeister series but also upon aerobiosis and the nature of the surface upon which they are grown (Brodie, 1948). Identical patterns of inhibition are obtained if shallow-layer fluid cultures are employed. The media under discussion possess lethal qualities which appear to be modified by a process akin to adsorption and the results obtained with solid media to depend in part upon the physical nature of the gel.

Electron microscope studies suggest that bile salts alter the permeability of the cell-wall, facilitating the entry of electrolytes. The resultant swelling or disruption of cells exposed to bile-salt + electrolyte mixtures and subsequently to distilled water is a measure of their electrolyte content. The ease with which organisms can be inhibited in the media seems to be directly related to their altered cell-wall permeability. The observations direct attention to physiological differences between rough and smooth variants of a single culture. They indicate that one factor upon which such differences depend is the greater permeability of the rough variant to electrolyte in the presence of bile salts.
\end{abstract}

A further attempt has been made to elucidate the mechanism of differential inhibition in media containing bile salts and electrolytes. Brodie (1948) showed that agar and silica gels gave consistent results, whereas the effect of gelatin was less certain. Agar and silica gels on setting extrude water by syneresis whereby their surfaces are 'wetted', but gelatin gels may have a 'dry' surface. To obtain the requisite patterns of differential inhibition, a 'wet' surface appears to be essential. Assuming that the fluid extruded by the agar and silica gels contains all the soluble constituents of the medium in their original concentrations, then it should be possible to reproduce the same patterns of inhibition by growing the organisms in corresponding fluid media. Furthermore, if, as indicated by previous work, aerobiosis is essential, then only by exposure of the organisms in shallow-layer cultures should the differential effect be obtained. Since the gelatin-containing medium remains fluid at $37^{\circ}$, the behaviour of the organisms in the presence of gelatin in the fluid state along with the other constituents was also open for study. With the Sonne III variants the inhibitory mechanism shows a selectivity which is partly lethal and differs in degree for either variant.

\section{Media and technique}

Unless otherwise indicated, all media were fluid and contained sodium tauroglycocholate (British Drug Houses Ltd., B.P.C. standard), sodium chloride and peptic digest of serum (Brodie, 1942). Each $6 \mathrm{ml}$. of complete medium 
contained: $1.5 \mathrm{ml}$. peptic digest of serum; $0.6 \mathrm{ml}$. of $5 \%(\mathrm{w} / \mathrm{v})$ sodium tauroglycocholate; $0.6 \mathrm{ml}$. of $3.6 \%(\mathrm{w} / \mathrm{v})$ sodium chloride; the requisite volume of electrolyte solution to give a known molar concentration; sufficient double glass-distilled water to bring the final volume to $6 \mathrm{ml}$. The reaction of all media was adjusted to $\mathrm{pH} 7 \cdot 6$. Media were steamed for $30 \mathrm{~min}$. before use. Where available, 'Analar' reagents (British Drug Houses, Ltd.) were used.

Sufficient of a $24 \mathrm{hr}$. agar culture to produce minimal visible turbidity was transferred on a chrome-iron wire loop to $9 \mathrm{ml}$. of sterile distilled water. After vigorous mixing, $0.1 \mathrm{ml}$. of this suspension was thoroughly dispersed in a bottle containing $90 \mathrm{ml}$. of sterile distilled water; from this $0.5 \mathrm{ml}$. was inoculated into the tube $\left(6 \times \frac{3}{4}\right.$ in.) containing the experimental medium. Thereupon $1 \mathrm{ml}$. from the inoculated tube was mixed in a Petri dish with $4 \mathrm{ml}$. of melted C.C.Y. agar (Gladstone \& Fildes, 1940), allowed to set and incubated for $24 \mathrm{hr}$. at $37^{\circ}$. The colony count at the end of this period was assumed to be the number of viable organisms $/ \mathrm{ml}$. of inoculated medium. All Petri dishes used had an internal diameter of $1 \frac{3}{4}$ in. and an internal depth of $\frac{3}{4}$ in. Further counts of the viable organisms remaining in the experimental medium were made in a similar fashion at intervals. Any departures from these methods are noted in the text.

Organisms studied. The organisms used were the same as in the previous work, namely: SR, a rough variant of a recently isolated Sonne III bacillus; SS, a smooth variant from the same parent strain; $\mathrm{C} 1$, Bacterium coli communes from human faeces; C2, Bacterium coli communius from human faeces; A1, Aerobacter sp. from milk; A2, Aerobacter sp. from water.

Standard patterns of inhibition. The patterns of inhibition to which reference will be made are: $(a)$ 'partial differentiation', which means that SR, SS, A1 and A 2 grew but $\mathrm{C} 1$ and $\mathrm{C} 2$ failed to grow; $(b)$ 'complete differentiation', indicating that all strains, except SS, failed to grow.

\section{RESULTS}

\section{Shallow and deep cultures}

Having inoculated the $6 \mathrm{ml}$. tubes of media and prepared the viable inoculum plates, $1 \mathrm{ml}$. volumes were spread in Petri dishes to give shallow cultures. These were incubated for $24 \mathrm{hr}$. in air saturated with water vapour at $37^{\circ}$. The $4 \mathrm{ml}$. volumes remaining were left in the tubes and also incubated for $24 \mathrm{hr}$. at $37^{\circ}$. Counts were then made from both shallow and deep cultures. Partial and complete differentiations occurred only with the shallow cultures. In the presence of $0.5 \%$ tauroglycocholate in shallow culture, partial differentiation resulted with $0.057 \mathrm{M}$ ammonium citrate, $0.066 \mathrm{M}$ potassium citrate, $0 \cdot 1 \mathrm{M}$ sodium citrate, $0 \cdot 33 \mathrm{~m}$ sodium sulphate and $0.53 \mathrm{~m}$ sodium chloride; and complete differentiation with $0.1,0.12,0.2,0.398$ and $0.66 \mathrm{M}$ concentrations of these salts respectively. These molar concentrations are identical with those required to produce the same differentiation on the surface of bile-salt agar media (Brodie, 1948). 


\section{Media containing gelatin}

Similarly compounded media containing $15 \%(\mathrm{w} / \mathrm{v})$ gelatin were tested, using $\mathbf{0 . 1}$ and $\mathbf{0 . 2} \mathrm{M}$. sodium citrate as the electrolyte and both shallow and deep culture. The shallow-layer cultures were incubated at $37^{\circ}$ without any precautions being taken to saturate the air with water vapour. The viable inoculum counts in this instance were made from distilled water (see next section). Partial differentiation was achieved with $0 \cdot 1 \mathrm{M}$ and complete differentiation

(a)

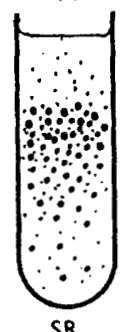

SR (b)

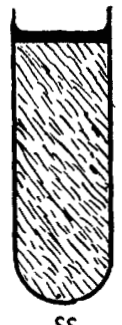

SS (c)

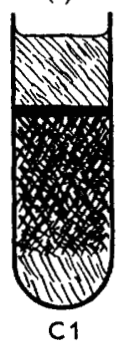

(d)

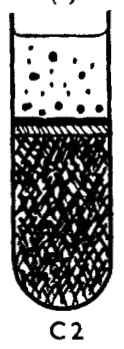

(e)

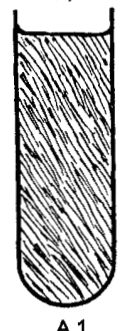

A1 (f)

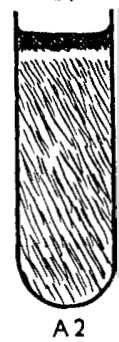

(1)

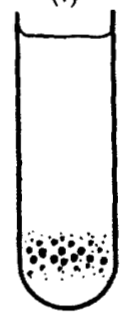

SR
(2)

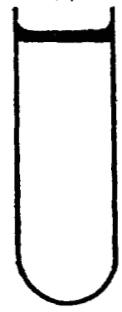

SS

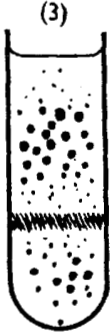

C1

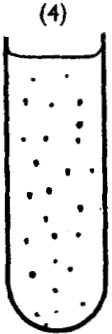

C2

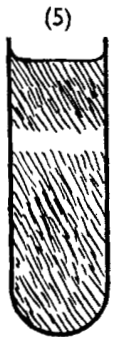

A 1
(6)

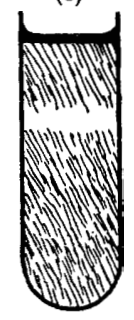

A 2

Fig. 1. Diagrammatic representation of 8-day growths of rough variant of Sonne III (SR), smooth variant of Sonne III (SS), Bact. coli communes (C1), Bact. coli communius (C2), Aerobacter sp. from milk (A 1) and Aerobacter sp. from water (A2) in $15 \%$ gelatin bile salt electrolyte media; $(a)-(f)$ contain $0.1 \mathrm{M}$ sodium citrate and (1)-(6) $0.2 \mathrm{M}$ sodium citrate. Densities of growth are indicated by corresponding densities of shading.

with $0.2 \mathrm{~m}$ sodium citrate only in the shallow cultures. In the deep cultures all six strains grew in $0.1 \mathrm{M}$ and all but $\mathrm{C} 2$ grew in $0.2 \mathrm{M}$ sodium citrate. Fluid gelatin medium in shallow layers gave the same result as fluid media and agar surface cultures.

The deep cultures, having been tested for growth after $24 \mathrm{hr}$. at $37^{\circ}$, were allowed to set and incubated a further 8 days at $22^{\circ}$; duplicate tubes heavily inoculated from thick distilled water suspensions were set up as controls, these being incubated directly at $22^{\circ}$ for 8 days. The results were substantially the same with or without preliminary incubation at $37^{\circ}$. However, with the higher concentration of citrate the air tolerance of the organisms, with the exception of SS, was depressed (Fig. I). It was previously observed (Brodie, 1948) that 
the differential effects obtained on the surface of agar gels were not reproduced using gelatin gels. On this occasion we have failed to corroborate the previous findings with gelatin. At present we cannot offer any explanation of this although both tests have been repeated several times.

\section{Viability}

During the experiments with fluid media it was noted that, whereas the initial turbidities in the $9 \mathrm{ml}$. distilled water tubes were of the same approximate densities, the counts made from the media varied markedly. This was most notable with SR, where some of the counts were nil. Distilled water and

Table 1. Numbers of Sonne III rough (SR) and Sonne III smooth (SS) variants surviving in deep and shallow cultures in peptic digest of serum broth containing $0.5 \%(w / v)$ sodium chloride, $0.5 \%(w / v)$ sodium tauroglycocholate and various concentrations of sodium sulphate

\begin{tabular}{|c|c|c|c|c|c|c|c|c|c|c|}
\hline & & & Iec & cultur & after & in.) & Shall & N cult & e afte & min.) \\
\hline - & Sodium & $\begin{array}{l}\text { Distilled } \\
\text { water }\end{array}$ & 0 & 5 & 10 & $\widetilde{15}$ & 0 & 5 & 10 & 15 \\
\hline $\mathrm{rai}$ & sulphate & control & & & ts & & & & ts & \\
\hline SR & 0.33 & 9000 & 1000 & 60 & 30 & 24 & 1100 & 280 & 86 & 44 \\
\hline SR & $0 \cdot 398$ & 9000 & 300 & $\gamma$ & 0 & 0 & 430 & 130 & 40 & 20 \\
\hline SS & $0 \cdot 33$ & 4000 & 2300 & 1800 & 1500 & 1100 & 2400 & 2400 & 2400 & 2400 \\
\hline SS & $0 \cdot 398$ & 4000 & 1500 & 1000 & 775 & 775 & 2400 & 2400 & 2400 & 2400 \\
\hline
\end{tabular}

the media were therefore examined. The electrolyte used was sodium sulphate. Suspensions of SR and SS were prepared as before and each inoculated into $6 \mathrm{ml}$. tubes of distilled water and also into bile-salt media containing 0.33 and 0.398 M-sodium sulphate. Counts of viable organisms were made immediately, and at 5, 10 and $15 \mathrm{~min}$. intervals. The counts from the distilled water tubes remained constant throughout the $15 \mathrm{~min}$. period, but the two media exhibited lethal action. The experiments recorded in Table 1 indicate that the media exhibit a lethal effect which depends on $(a)$ the variant exposed, $(b)$ the access of air and $(c)$ the concentration of added electrolyte. We realize that, owing to the susceptibility of rough strains to salt agglutination, the diminution in colony count with SR might be partly accounted for thereby. The suspensions were therefore prepared to contain relatively few organisms- $-9000 / \mathrm{ml}$.-- to diminish spontaneous aggregation. Viewed in relation to the findings as shown by culture and observation with the electron microscope, the balance of evidence is that the medium was lethal.

\section{Relation of inoculum to lethal effect}

It was decided to try the effect of adding known numbers of SS cells to the medium containing $0.398 \mathrm{~m}$ sodium sulphate and to test the medium after each exposure for any alteration in its lethal effect. A batch of the fluid medium containing $0.5 \%$ tauroglycocholate and 0.398 m sodium sulphate was divided 
into parts $\mathbf{A}$ and $\mathbf{B}$. To part A, packed washed living SS cells were added to yield, as calculated by Brown's scale, a concentration of 45,000 million organisms $/ \mathrm{ml}$. After thorough mixing and $5 \mathrm{~min}$. exposure, the organisms were removed by high-speed centrifugation. The supernatant was collected, its volume measured, then heated at $65^{\circ}$ for $45 \mathrm{~min}$. to sterilize. This procedure was repeated but with a small dose of organisms, the number being determined by counting from distilled water, and the number of survivors after $5 \mathrm{~min}$. exposure to the medium counted. Finally, a third addition of organisms was made, similarly estimated and the effect of 5 min. exposure determined. Part B of the medium was treated in the same way except that all three doses of added organisms were small.

Part A, after treatment with the massive dose of cells, was no longer lethal for the subsequent inocula: of 11,500 and 12,200 organisms $/ \mathrm{ml}$. added as the second and third inocula, 11,400 and $12,000 / \mathrm{ml}$. survived the $5 \mathrm{~min}$. exposures, a survivor rate of almost $100 \%$. Part B, with initial inocula of $6250,14,000$ and 12,500 organisms $/ \mathrm{ml}$, yielded $3000,10,000$ and 9500 survivors $/ \mathrm{ml}$. respectively; survival rates of 48,71 and $76 \%$. Part $A$, now rendered devoid of lethal effect for strain SS, was tested for lethal effect on SR and was found to be as lethal to SR as the untreated medium; this was equally true in respect of $5 \mathrm{~min}$. exposure and of $24 \mathrm{hr}$. exposure in shallow culture at $37^{\circ}$ with initial inocula of $12,000 / \mathrm{ml}$. in both. The possibility of salt agglutination must, however, be borne in mind.

\section{Observations with the electron microscope.}

Preparations were examined with the electron microscope (Metrovick E.M.2) at $50 \mathrm{kV}$. accelerating potential and a beam-current of 0.2 ma., employing minimum magnification which, with the length of specimen holder employed, was approximately 6000 diameters. Distilled water suspensions of SR and SS cells were made and examined after vacuum drying on collodion films. These served as the basis of comparison with the other preparations which were made by suspending washed SR and SS organisms in $0.3 \mathrm{M}$ and $0.398 \mathrm{M}$ sodium sulphate bile-salt media for $30 \mathrm{~min}$. at $37^{\circ}$, removing them by centrifugation and resuspending them in distilled water prior to examination as above.

Photographs of preparations are shown on Plate 1. The SS strain after treatment as above is little altered (Pl. 1, figs. 7-10). The SR strain after similar exposure (figs. 1-5), shows marked swelling and internal distortion with 0.33 м sodium sulphate + bile salt (fig. 4); with 0.398 м sodium sulphate + bile salt all but a few are burst, only the cell wall remaining (fig. 5). Exposure of these organisms to bile salt or electrolyte alone produced no such effects (figs. 2, 3). Exposure of the coliform bacilli (fig. 6) and the Aerobacter sp. (fig. 11) to bile salt $+0.398 \mathrm{~m}$ sodium sulphate caused swelling and internal distortion of these organisms similar to that noted with the SR strain treated with $0.33 \mathrm{M}$ sodium sulphate+bile salt. Throughout this investigation, the serological characters of the SR and SS strains were checked by agglutination. 
Journal of General Microbiology, Vol. 3, No. 1

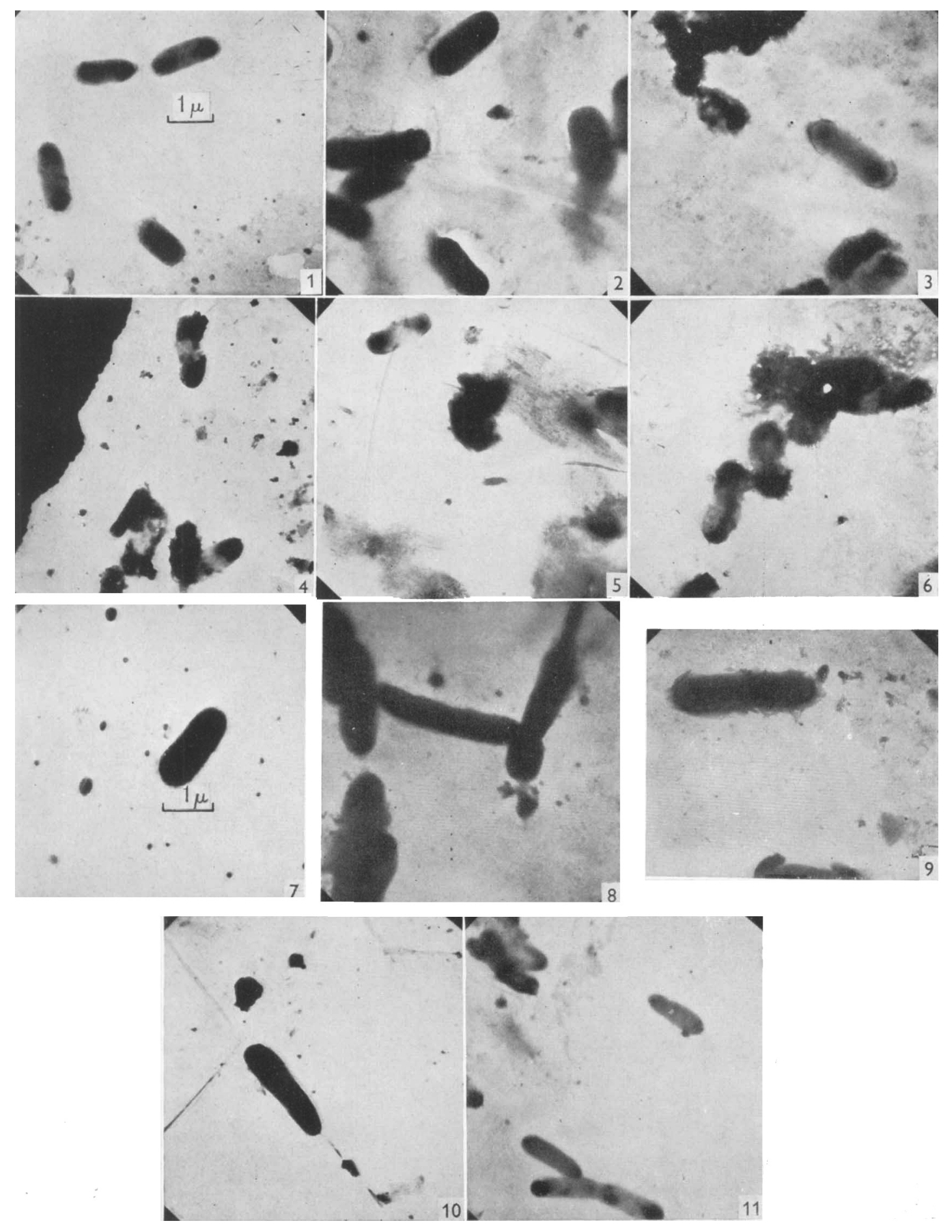

Figs. 1-11

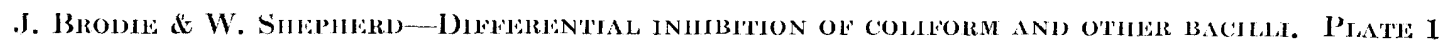


The authors wish to thank Prof. W. J. Tulloch for advice and criticism and Prof. G. D. Preston of the Physics Department and his staff for permission to use the electron microscope and for assistance in its use. The Department of Physics is indebted to the Department of Scientific and Industrial Research for the loan of a Metropolitan-Vickers type E.M. 2 electron microscope.

\section{REFERENCES}

Brodie, J. (1942). Modified Leifson media for the isolation of $B$. dysenteriae and pathogenic members of the colon-typhoid group. J. Path. Bact. 54, 499.

Brodie, J. (1948). Observations on the differential inhibition of coliform bacilli and rough variants of intestinal pathogens. J. gen. Microbiol. 2, 1.

Gradstone, G. P. \& Findes, P. (1940). A simple culture medium for general use without meat extract or peptone. Brit. J. exp. Path. 21, 161.

\section{EXPLANATION OF PLATE}

Electron micrographs of strains SR, SS, C2 and A2 made from distilled water suspensions, either $A$, direct from agar cultures, or $B$, after exposure for $30 \mathrm{~min}$. at $37^{\circ}$ in fluid medium containing (1) $0.5 \%$ tauroglycocholate only, (2) 0.398 m sodium sulphate only, (3) $0.5 \%$ tauroglycocholate and $0.33 \mathrm{~m}$ sodium sulphate or (4) $0.5 \%$ tauroglycocholate and $0 \cdot 398$ M sodium sulphate. Magnifications are indicated by the $1 \mu$ mark on figs. 1 and 7 .

Fig. 1. Strain SR treated as A. Fig. 2. SR after B(1). Fig. 3. SR after B(2). Fig. 4, SR after $B(3)$, swelling and internal distortion are evident. Fig. 5. SR after $B(4)$, one organism shows swelling and internal distortion while the others are burst, only their cell-membranes remaining. Fig. 6. $\mathrm{C} 2$ after $\mathrm{B}(4)$, showing swelling and internal distortion: Fig. 7. SS prepared as A. Fig. 8. SS after B(1). Fig. 9. SS after B(2). Fig. 10. SS after B (4), showing neither swelling nor distortion (cf. Fig. 5). Fig. 11. A2 after $B(4)$ shows some swelling and internal distortion.

(Received 14 April 1948) 